\title{
Perekayasaan sistem pendidikan nasional untuk mencerdaskan kehidupan bangsa
}

\author{
Bambang Hermanto* \\ Program Studi Megister Ilmu Politik, Universitas Airlangga \\ *Corresponding Author. e-mail: bambang.hermanto-2017@fisip.unair.ac.id
}

\begin{abstract}
Abstrak
Artikel ini menganalisis kebijakan pendidikan di Indonesia. Sistem pendidikan nasional harus mampu menjamin pemerataan kesempatan pendidikan, peningkatan mutu serta relevansi dan efisiensi manajemen pendidikan untuk menghadapi tantangan sesuai dengan tuntutan perubahan kehidupan lokal, nasional, dan global sehingga perlu dilakukan pembaharuan pendidikan secara terencana, terarah, dan berkesinambungan. Metode yang digunakan dalam penelitian ini adalah analisis media dan studi literatur. Teknik pengumpulan data yang digunakan berasal dari data primer yang berupa observasi atas fenomena yang terjadi dan data sekunder berupa dokumentasi yang valid. Hasil analisis menunjukkan bahwa Penerapan sistem pendidikan nasional yang baik dan mencerahkan bagi peserta didik tidak dengan meliberalkan sistem pendidikan, tetapi membangun pemikiran bahwa tidak selalu pemerintah, orang tua dan guru lebih tahu yang terbaik bagi peserta didik. Kementerian Pendidikan dan Kebudayaan perlu melakukan reformasi secara komprehensif terkait dengan pelaksanaan sistem pendidikan nasional dengan cara yang efisien, transparan, dan akuntabel. Pendidikan harus mendapatkan perhatian yang serius bagi setiap bangsa, karena dengan pendidikan akan dapatdilihat maju mundurnya suatu bangsa. Tentu saja bangsa Indonesia tidak ingin hidup terbelakang akibat aspek pendidikan tidak mendapat porsi yang cukup dengan beriringnya berbagai kemajuan di bidang lain. Sehingga penting suatu perekayasaan sistem pendidikan nasional untuk mencerdaskan kehidupan bangsa.
\end{abstract}

Kata kunci: perekayasaan, kehidupan bangsa, mencerdaskan, sistem pendidikan nasional

\begin{abstract}
This article analyzes the education policy in Indonesia. The national education system must be able to guarantee equal opportunity for education, quality improvement and the relevance and efficiency of education management to face challenges in accordance with the changing demands of local, national and global life so that it is necessary to plan education in a planned, directed and continuous manner. The method used in this research is media analysis and literature study. Data collection techniques used are derived from primary data in the form of observations of phenomena that occur and secondary data in the form of valid documentation. The results of the analysis show that the application of a good and enlightening national education system for students is not to liberalize the education system, but builds the thought that it is not always the government, parents and teachers know better what is best for students. The Ministry of Education and Culture, and the Ministry of Research Technology and Higher Education need to carry out comprehensive reforms related to the implementation of the national education system in an efficient, transparent and accountable manner. Education must get serious attention for every nation because with education it can be seen the progress of a nation. Of course, the Indonesian nation does not want to live backward due to the aspect of education not getting enough portion with the progress of various advances in other fields. So it is important engineering of the national education system to educate the life of the nation.
\end{abstract}

Keywords: engineering, nation life, education, national education system

(C) This is an open-access article under the CC-BY-SA license.

doil https://doi.org/10.21831/foundasia 


\section{PENDAHULUAN}

Negara-negara di dunia menyadari bahwa pendidikan diyakini memiliki kemampuan untuk menyiapkan sumber daya manusia (SDM). Proses pendidikan diharapkan mampu memberi petunjuk bagi keberlangsungan kehidupan sesuai dengan tata nilai ideologis dan kultural bangsa, memberi kesadaran kepada setiap individu akan potensi "kemanusian" yang dimilikinya, dan lebih dari itu pendidikan harus mampu merangsang individu untuk mempergunakan potensi tersebut sesuai dengan tata nilai kemanusian. Secara material, pendidikan harus dapat memberikan penge-tahuan yang memajukan dan mempertinggi kualitas hidup, baik dalam skala kehidupan pribadi, bermasyarakat maupun bernegara.

Pendidikan merupakan kebutuhan setiap individu dan selalu berubah mengikuti perkembangan zaman, ilmu pengetahuan teknologi dan budaya masyarakat. Pendidikan sangat penting dalam-meningkatkan kualitas sumber daya manusia. Kualitas pendidikan menjadi dasar utama dalam menambah wawasan dan ilmu pengetahuan yang akan membentuk karakter penerus bangsa yang siap menghadapi situasi apapun.Pemerintah perlu melakukan perbaikan secara berkesinambungan terhadap semua komponen yang ada pada pendidikan. Tujuan pendidikan nasional dapat tercapaidengan disusunnya suatu strategi yang berkaitan dengan permasalahanpermasalahan pendidikan di Indonesia meliputi permasalahan mutu pendidikan, pemerataan pendidikan dan manajemen pendidikan.

Undang-undang Nomor 2 Tahun 1989 tentang Sistem Pendidikan Nasional dianggap tidak memadai lagi dan perlu diganti serta perlu disempurnakan agar sesuai dengan amanatperubahan Undang-Undang Dasar Negara Republik Indonesia Tahun 1945. Pembukaan Undang-Undang Dasar Negara Republik Indonesia tahun 1945mengamanatkan Pemerintah Negara Indonesia yang melindungi segenap bangsa Indonesiadan seluruh tumpah darah Indonesia dan untuk memajukan kesejahteraan umum,mencerdaskan kehidupan bangsa, dan ikut melaksanakan ketertiban dunia yang berdasarkankemerdekaan, perdamaian abadi dan keadilan sosial. Pemerintah mengusahakan dan menyelenggarakan satu sistem pendidikannasional yang meningkatkan keimanan dan ketakwaan kepada Tuhan Yang Maha Esa sertaakhlak mulia dalam rangka mencerdaskan kehidupan bangsa yang diatur dengan undang-undang.

Sistem pendidikan nasional harus mampu menjamin pemerataan kesempatanpendidikan, peningkatan mutu serta relevansi dan efisiensi manajemen pendidikan untukmenghadapi tantangan sesuai dengan tuntutan perubahan kehidupan lokal, nasional, danglobal sehingga perlu dilakukan pembaharuan pendidikan secara terencana, terarah, danberkesinambungan. Selain itu, berkaitaan dengan sistem pendidikan nasional yaitu Pasal 20, Pasal 21, Pasal 28 C ayat (1), Pasal 31, dan Pasal 32 Undang-Undang Dasar NegaraRepublik Indonesia Tahun 1945.Akhirnya pemerintah menetapkan Undang-Undang Republik IndonesiaNomor 20 Tahun 2003TentangSistem Pendidikan Nasional.

Pendidikan adalah usaha sadar dan terencana untuk mewujudkan suasana belajardan proses pembelajaran agar peserta didik secara aktif mengembangkan potensi dirinyauntuk memiliki kekuatan spiritual keagamaan, pengendalian diri, kepribadian, kecerdasan,akhlak mulia, serta keterampilan yang diperlukan dirinya, masyarakat, bangsa dan negara.Pendidikan nasional adalah pendidikan yang berdasarkan Pancasila dan Undang-Undang Dasar Negara Republik Indonesia Tahun 1945 yang berakar pada nilai-nilai agama,kebudayaan nasional Indonesia dan tanggap terhadap tuntutan perubahan zaman.Sistem pendidikan nasional adalah keseluruhan komponen pendidikan yang salingterkait secara terpadu untuk mencapai tujuan pendidikan nasional.

Berdasarkan pasal 5 Undang-Undang No. 20 Tahun 2003 tentang Sistem Pendidikan Nasional, setiap warga negara mempunyai hak yang sama untuk memperoleh pendidikan yang bermutu.Warga negara yang memiliki kelainan fisik, emosional, mental, intelektual, dan/atau sosial berhak memperoleh pendidikan khusus.Warga negara di daerah terpencil atau terbelakang serta masyarakat adat yang terpencil berhakmemperoleh pendidikan layanan khusus.Warga negara yang memiliki potensi kecerdasan dan bakat istimewa berhak memperolehpendidikan khusus.Setiap warga negara berhak mendapat kesempatan meningkatkan pendidikan sepanjang hayat.

Standar nasional pendidikan terdiri atas standar isi, proses, kompetensi lulusan, tenaga kependidikan, sarana dan prasarana, pengelolaan, pembiayaan, dan penilaian pendidikan yang harus 
ditingkatkan secara berencana dan berkala. Standar nasional pendidikan digunakan sebagai acuan pengembangan kurikulum, tenaga kependidikan, sarana dan prasarana, pengelolaan, dan pembiayaan. Pengembangan standar nasional pendidikan serta pemantauan dan pelaporan pencapaiannya secara nasional dilaksanakan oleh suatu badan standardisasi, penjaminan, dan pengendalian mutu pendidikan.

Pendidikan nasional berfungsi mengembangkan kemampuan dan membentuk watak serta peradaban bangsa yang bermartabat dalam rangka mencerdaskan kehidupan bangsa, bertujuan untukberkembangnya potensi peserta didik agar menjadi manusia yang beriman dan bertakwa kepadaTuhan Yang Maha Esa, berakhlak mulia, sehat, berilmu, cakap, kreatif, mandiri, dan menjadi warga negara yang demokratis serta bertanggung jawab. Berdasarkan latar belakang tersebut, penulis menilai penting untuk menggambarkan secara gamblang perekayasaan sistem pendidikan nasional untuk mencerdaskan kehidupan bangsa.

\section{METODE PENELITIAN}

Penelitian ini terdiri dari beberapa tahap yang dimulai dengan tahap pengumpulan data. Kemudian dilanjut-kan dengan proses analisis data. Penulis menggunakan pendekatan metode kualitatif. Melalui metode kualitatif akan menghasilkan data deskriptif dalam bentuk tertulis mengenai perekayasaan sistem pendidikan nasional untuk mencerdaskan kehidupan bangsa. Teknik pengumpulan data yang digunakan berasal dari data primer yang berupa observasi atas fenomena yang terjadi dan data sekunder berupa dokumentasi yang valid. Pengamatan terkait kebijakan pendidikan di Indonesia diamati melalui media massa, sedangkan dokumentasi dalam bentuk sastra, karya ilmiah, jurnal nasional dan internasional. Validasi data dan temuan yang diperoleh peneliti menggunakan teknik triangulasi sumber. Keseluruhan proses analisis data melibatkan beberapa upaya untuk menginterpretasi data dalam bentuk teks atau gambar. Peneliti perlu menyiapkan data yang akan dianalisis untuk memahami dan menginterpretasi makna sebenarnya. Setelah itu, data dianalisis dengan menggunakan teori yang telah ditetapkan.

\section{HASIL DAN PEMBAHASAN}

\section{Dilematika Sistem Pendidikan Nasional}

Dilihat dari pejalanan sejarah pendidikan di Indonesia, arah pendidikan disesuaikan dengan keadaan dan kepentingan penguasa, ketika penguasa memerlukan suatu kekuatan politik ke arah itulah pendidikan di arahkan. Kalau ditilik lebih dalam aspek politik pendidikan, pendidikan diorientasikan sebagai alat untuk kepentingan tertentu, seperti kepentingan ideologi dan kepentingan politik untuk mempertahankan status quo.

Dewasa ini pendidikan nasional merupakan subordinasi dari kekuatan-kekuatan politik praktis. Hal ini berartipendidikan telah dimasukkan di dalam kancah perebutan kekuasaan oleh partai-partaipolitik. Pendidikan bukan lagi untuk membangun manusia Indonesia seutuhnya,tetapi untuk membangun kekuatan daripartai politik praktis tertentu untuk kepentingan golongan atau punkelompoknya sendiri.

Diakui atau tidak, sistem pendidikan yang berjalan di Indonesia saat ini memangadalah sistem pendidikan yang sekular-materialistik. Bila disebut bahwa sistem pendidikannasional masih mewarisi sistem pendidikan kolonial, maka watak sekuler-materialistik inilahyang paling utama, yang tampak jelas pada hilangnya nilai-nilai transendental pada semuaproses pendidikan.

Secara kelembagaan, sekularisasi pendidikan menghasilkan dikotomi pendidikanyang sudah berjalan puluhan tahun, yakni antara pendidikan agama di satu sisi denganpendidikan umum di sisi lain. Pendidikan agama melalui madrasah, institut agama danpesantren dikelola oleh Kementerian Agama, sementara pendidikan umum melalui sekolahdasar, sekolah menengah dan kejuruan serta perguruan tinggi umum dikelola oleh Kementerian Pendidikan dan Kebudayaan serta Kementerian Riset Teknologi dan Pendidikan Tinggi.

Selain itu, penerapan kebijakan sistem zonasi dalam Penerimaan Peserta Didik Baru (PPDB) 2018/2019 menimbulkan perdebatan mengenai masalah jarak antara tempat tinggal calon peserta didik dengan sekolah, perbedaan penafsiran daerah atas aturan zonasi,dan penyalahgunaan Surat Keterangan Tidak Mampu (SKTM). Penerbitan SKTM harus selektif dan sanksi atas 
penyalahgunaannya harus ditegakkan. Komisi X DPR RI perlu mendorong Kemendikbud untuk melakukan evaluasi secara menyeluruh sistem zonasi dalam PPDB.

Adanya campur tangan politik dalam proses implementasi kebijakan membuat kegiatan penerimaan peserta didik baru menuai konflik.DinasPendidikan Daerah perlu mengevaluasi kembali proyeksi lulusan sekolah dengan ketersediaan sekolah guna menentukan zonasi. Kondisi sekolahdi setiap daerah juga perlu ditinjaukembali, apakah sudah memenuhi standar nasional pendidikan.

Nilai-nilai yang pantas dan benar ditanamkan di benak para peserta didikharus melihat pada kekhususan-kekhususan dan aneka potensi, kreativitas, serta kemampuan yang berbeda dari tiap-tiap peserta didik. Penerapan sistem pendidikan nasional yang baik dan mencerahkan bagi peserta didik tidak dengan meliberalkan sistem pendidikan, tetapi membangun pemikiran bahwatidak selalu pemerintah, orang tua dan guru lebih tahu apa yang terbaik bagi peserta didik.

\section{Reformasi Sistem Pendidikan Nasional}

Sistem pendidikan di Indonesia dewasa ini tampak ada kesenjangan antara keinginan dan realita. Secara makro dapat dilihat dalam aspek pengelolaan, peran pemerintah dan masyarakat, kurikulum atau materi ajar, pendekatan dan metodologi pembelajaran, sumber daya manusia, lingkungan kampus atau sekolah, dana, dan akreditasi. Kesenjangan dalam sistem pendidikan tersebut disebabkan karena faktor politik, ekonomi, sosial-budaya dan sebagainya yang selalu berubah sesuai dengan perubahan dan perkembangan zaman.

Pendidikan yang materialistik adalah buah dari kehidupan sekularistik yang terbukti telah gagal menghantarkan manusia menjadi sosok pribadi yang utuh. Hal ini disebabkan oleh dua hal. Pertama, paradigma pendidikan yang keliru di mana dalam sistem kehidupan sekuler, asas penyelenggaraan pendidikan juga sekuler. Tujuan pendidikan yang ditetapkan juga adalah buah dari paham sekularistik, yakni sekedar membentuk manusia-manusia yang berpaham materialistik dan serba individualistik.

Kedua, kelemahan fungsional pada tiga unsur pelaksana pendidikan, yakni (1)kelemahan pada lembaga pendidikan formal yang tercermin dari kacaunya kurikulum sertatidak berfungsinya guru dan lingkungan sekolah/kampus sebagai medium pendidikansebagaimana mestinya, (2) kehidupan keluarga yang tidak mendukung, dan (3) keadaanmasyarakat yang tidak kondusif .

Tidak berfungsinya guru/dosen dan rusaknya proses belajar mengajar tampak dariperan guru yang sekadar berfungsi sebagai pengajar dalam proses transfer ilmu pengetahuan(transfer of knowledge), tidak sebagai pendidik yang berfungsi dalam transfer ilmupengetahuan dan kepribadian (transfer of personality), karena memang kepribadianguru/dosen sendiri banyak tidak lagi pantas diteladani.

Arah dan bentuk transformasi sistem pendidikan nasionaldari waktu ke waktu banyak dipengaruhi oleh pergantian kepemimpinan nasional. Sehingga problematika di bidang pendidikan belum dapat terselesaikan.Oleh karena itu, penyelesaian problem pendidikan yang mendasar harus dilakukan pula secara fundamental, dan itu hanya dapat diujudkan dengan melakukan perbaikan secara menyeluruh yang diawali dari perubahan paradigma.

Secara paradigmatik, pendidikan harus dikembalikan pada nilai-nilai kemanusiaan yang demokratif yangmenjadi dasar penentuan arah dan tujuan pendidikan, penyusunan kurikulum danstandar nilai ilmu pengetahuan serta proses belajar mengajar, termasuk penentuan kualifikasiguru/dosen serta budaya sekolah/kampus yang akan dikembangkan. Sekalipun pengaruhnya tidak sebesar unsur pendidikan yang lain, penyediaan sarana dan prasarana juga harus mengacu pada asas di atas.

Solusi strategis fungsional sebenarnya sama dengan menggagas suatu sistem pendidikan alternatif yang bersendikan pada dua cara yang lebih bersifat strategis dan fungsional, yakni: Pertama, membangun lembaga pendidikan unggulan di mana semua komponen berbasis paradigma kemanusiaan yang demokratif, yaitu: (1) kurikulum yang paradigmatik, (2) guru/dosenyang profesional, (3) proses belajar mengajar secara demokratif, dan (4)lingkungan dan budaya sekolah/kampus yang kondusif bagi pencapaian tujuan pendidikansecara optimal. Dengan melakukan optimasi proses belajar mengajar serta melakukan upaya meminimasi pengaruh-pengaruh negatif yang ada, dan pada saat yang sama meningkatkan pengaruh positif pada anak didik, 
diharapkan pengaruh yang diberikan pada pribadi anakdidik adalah positif sejalan dengan arahan nilai-nilai kemanusiaan yang demokratif.

Kementerian Pendidikan dan Kebudayaan, serta Kementerian Riset Teknologi dan Pendidikan Tinggi perlu melakukan reformasi secara komprehensif terkait dengan pelaksanaan sistem pendidikan nasional dengan cara yang efisien, transparan, dan akuntabel. Sehingga baik bagi kementerian maupun para pemangku kepentingan pendidikan yang harus dilayaninya. Struktur organisasi kementerian disusun berdasarkan analisis yang mendalam dan komprehensif dengan mengedepankan. Keutuhan penanganan keseluruhan proses pendidikan oleh tiap unit utama (Integratif). Kesamaan tujuan pendidikan dalam satu unit (Inklusif/nondiskriminatif). Perbandingan kinerja dalam penanganan tugas yang sama untuk memacu motivasi kerja (Motivatif). Pemanfaatan sumber daya terbatas untuk mencapai tujuan pendidikan (Efisien dan Efektif). Pembagian tugas dan fungsi kedalam unit utama dengan pendekatan yang konsisten (Konsistensi).

\section{Masa Depan Sistem Pendidikan Nasional Untuk Mencerdaskan Kehidupan Bangsa}

Berbagai upaya pembaharuan sistem pendidikan nasional telah dilaksanakan untuk meningkatkan kualitas pendidikan, tetapi sejauh ini belum menampakkan hasilnya.Mengapa kebijakanpembaharuan sistem pendidikan di tanahair kita dapat dikatakan senantiasagagal menjawab problemmasyarakat? Kegagalan tersebut bukan semata-mata terletak padabentuk pembaharuan pendidikannyasendiri yang bersifat erratic, tambalsulam, melainkan lebih mendasarlagi kegagalan tersebut dikarenakanketergantungan penentu kebijakanpendidikan pada penjelasanparadigma peranan pendidikan dalamperubahan sosial yang sudah usang.Ketergantungan ini menyebabkan adanya harapan-harapan yang tidak realistis dan tidak tepat terhadap efikasi pendidikan.

Pendidikan cenderung menjadi sarana stratifikasi sosial. Kunci dasar paradigmapendidikan kita di masa depan adalahpendidikan yang demokratif, karena menurut Freire dalam bukunya yang di edit oleh Escobar,dkk. (1998)tidak akan terbangun intelektualitastanpa membebaskan pikirannya daripenjajahan. Peranan pendidikan yangdemokratik ditandai keikutsertaanpelaku pendidikan dan peserta didik dalam pengambilan keputusan untuk keperluan dirinya. Karena mereka memiliki objek dan persoalan sendiri yang ingin mereka pelajari.

Belenggu pendidikan bersumber dari beberapa faktor,misalnya pembelengguan yangberasal dari (1) sistem perundang-undangan, (2) sentralisasi, (3) uniformitas, (3) managejen dan supervisipendidikan, dan (4) kesalahan ukuran penilaian keberhasilan pendidikan. Dari sistem perundang-undangan diantaranya adalah (1) tidak disentuhnya pendidikan luarsekolah, (2) terlalu syaratnya kurikulum. Belenggu sentralisasi danuniformitas dapat mencekaltumbuhnya diversifikasi yang akan menghambat terjadinya keunggulan. Belenggu sistem manjemen dan supervisi yang terlalu sentristerhadap administrasi pendidikan, berakibat kurang memperhatikan terhadap proses pembelajaran.

Desentralisasi program pendidikan sangat dibutuhkan untuk melaksanakan pendidikan yang terbaik dan otonom. Sehingga tidak sekadar alat untuk mempertahankanstatus quopenguasa. Akibatnya kreativitas kegiatan pembelajarandenganoptimal menjadi terhambat, bahkan kegiatan pembelajaran sebatas melaksanakan sesuatu sesuaidengan petunjuk formal.Penyimpangan dari petunjuk formal meskipun menghasilkan kebaikan dianggap pelanggaran yang mempunyai sanksi administratif. Sistem pendidikan tersebut tidak membangun pengalaman. Padahal menurut Brooks \& Brooks (1994) "education must invite students to experience to world's richness, empower them to ask their own questions and seek their own answers, and challenge them to understand the world's complexities".

Proses pemberdayaan peserta didikdapat ditumbuhkan melalui pengalaman. Pendidikan adalahproses mencari pengalaman. Sedangkan sentralisasi pendidikan tidak mengenal lingkungan nyatadari karakteristik kehidupannya masing-masing, budaya masing-masing,dan akibatnya sulit untuk menumbuhkan cinta tanah air dan bangsa. Bahkan sulit untuk membangun tumbuhnya rasakesatuan dan persatuan. Pendidikan menjadi sangat abstrak, dan justru basis masyarakatnya tidak terhayati dengan baik.

Pola uniformitas tetap dipertahan untuk memperoleh standar mutu pendidikan. Diversifikasi yang justru menghasilkan banyak acuan ditinggalkan. Padahal diversivikasi akan muncul berbagai kreativitas yang dapat menghasilkan alternatif. Hasil kreativitas yang baik dapat diacu bagi mereka 
yang ketinggalan. Diversifikasi akan menghasilkan berbagai unggulan yang dapat digunakan untuk tersediannya referensi nasional.

Kemudian fleksibilitas adalah tanda kehidupan yang akan mampu mengikuti dinamika hidup di masa depan. Uniformitas selalu diukur daristandar pengetahuan. Padahal kemampuan pengetahuan belumdapat digunakan untuk mengukur keberhasilan pendidikan. Dengan ukuran itu, maka anak yang pandai tetap pandai dan anak yang bodoh tetap bodoh. Bahan ajar yang sulit tetap sulit. Padahal keberhasilan pendidikan seharusnyadi perhatikan dari mudahnya bahan ajar yang sulit dan dari meningkatnya kemampuan anak yang tidak pandai.

Kesan pendidikan sebagai kewajiban daripada kebutuhan, menyebabkan terjadinya berbagai penyalahgunaan, sehingga peserta didik dijadikan objek pendidikan. Sangat langka dijumpai pendidikan yang berorentasi kepada kepentingan peserta didik. Lebih-lebih dengan pola pengajaran sistem penyampaian,linieritas terjadi antara buku teks diatas dengan guru di bawahnya dan kedudukan peserta didik paling bawah. Dalam pola struktur pendidikan semacam itu seiring terdengar terjadinya pembodohan sistematis pada generasi bangsa kita.

Pendidikan untuk peserta didik memiliki prinsip terbentuknya individu belajar yang menjadi awal dari terbentuknya masyarakat belajar yang dibutuhkan dalam hidup di era global. Menurut Freire (1999) pendidikan yang memperhatikan keperluan peserta didik atau yang memperhatikan hak azasi peserta didik adalah pendidikan yang humanis. Pendidikan yang humanis ini adalahsebagai wujud pembebasan terhadap kaum yang tertindas, yang memberikan kebebasan yang luas untuk berfikir kritis.

Bahkan menurut Steinberg (1996) pemikiran reformasi sistem pendidikan dalam sekolah ataukelas harus diorientasikan kemungkinannya untuk meningkatkan kinerja peserta didik (student performance). Sistem pendidikan saat ini didominasi oleh guru banyak berbicara, senada dengan Brooks \& Brooks (1994) dari pernyataan Flanders danGoodlad "American classrom is dominated by teacher talk". Bahanajar yang digunakan sangattekstual. Peserta didik lebih banyak menerima berita dari teks yang digunakan oleh guru. Hal ini jugadisitir Brooks \& Brooks (1994) dan Ben Peretz "most teachers rely heavily on textbook". Peserta didik belajar informasi secara tekstual dari buku teks yang diwajibkan, bahkan lepasdari lingkungan mereka. Padahal justru persoalan belajar sangat kayadi sekitar peserta didik sehari-hari. Peserta didik diarahkan menguasai teks lepas dari pengalaman mereka. Konsep sederhana apapun harus dituangkan dari buku teks yang lebih mementingkan narasi, dan tidak berorentasi kepada konsep denganunsur-unsur konsep pendukung.

Selain itu, pendidikan "constructivisme" merupakan proses pembelajaran induktif, yang berarti mengangkat tinggi nilai-nilai faktual-empirik. Pola ini berkaitan dengan pendidikan konseptual. Program pembelajaran memiliki peran untuk mengembangkan kompetensi dan tujuan pembelajaran untuk peserta didik (Herwin, 2019). Apabila peserta didik belajar tidak konseptual jangan diharapkan mereka mampu menyusun konsepsendiri. Berbeda dengan pendidikan yang reseptif hanya memperkuat hafalan, dan apabila hafalannya telah hilang,maka mereka tidak punya apa-apalagi.

Brooks \& Brooks (1994) mempersoalkan apakah yang dimaksud dengan belajar dan apakah yang dimaksud dengan educated? Mereka juga mempersoalkan bagaimana peserta didik belajar dan bagaimana guru mengajar. Padadasarnya dinyatakan bahwa "contruction of understanding is the core element in a highly complex process". Dalam bagianyang lain mereka juga mengatakan bahwa "alternative interpretations of social phenomena are rarely considered".

Oleh karna itu paradigma"constructivisme" sebagai caramengajar tidak hanya diberlakukan pada mata pelajaran tertentu akantetapi menjadi model mengajar secara umum, terutama cara untukmencapai "subject matter objectives"yang selanjutnya dapat dijamin kemungkinan fungsionalnya tujuan behavioral (behavioral objectives) dari setiap proses pembelajaran.

Dalam proses pendidikan yang demikian, maka pengalaman dankenyataan menjadi bahan dasar pendidikan yang penting. Tingkat kepuasan manusia yang cenderung semakin materialistis menuntut perlunya dikembangkan kepuasan spiritual menjadi alternatifnya. Manusia tidak hanya dituntut mampu secara rasional menganalisis keadaan yang mendorong tumbuhnya kepuasan materiil. Akan tetapi lebih dari itu, mereka di tuntut untuk mampu memperlihatkan kemampuannya untuk menangkap isyarat spiritual, dengan meningkatkan kecerdasan spiritualnya. Dalam 
menghadapi kehidupan nyata manusia seharusnya tetap memiliki hubungan langsung dengan Sang Pencipta. Namun demikian,pengembangan kecerdasan spiritual ini belum ada dalam dimensi tujuan instruksional, karena acuan pendidikan memang notebene masih menggunakan pola fikir yang sekuler.

Pendidikan harus mendapatkan perhatian yang serius bagi setiap bangsa,karena dengan pendidikan akan dapat dilihat maju mundurnya suatu bangsa.Tentu saja bangsa Indonesia tidak inginhidup terbelakang akibat aspek pendidikan tidak mendapat porsi yang cukup dengan beriringnya berbagai kemajuan di bidanglain. Sehingga penting suatu perekayasaan sistem pendidikan nasional untuk mencerdaskan kehidupan bangsa.

\section{SIMPULAN}

Pendidikan nasional berfungsi mengembangkan kemampuan dan membentuk watak serta peradaban bangsa yang bermartabat dalam rangka mencerdaskan kehidupan bangsa, bertujuan untuk berkembangnya potensi peserta didik agar menjadi manusia yang beriman dan bertakwa kepada Tuhan Yang Maha Esa, berakhlak mulia, sehat, berilmu, cakap, kreatif, mandiri, dan menjadi warga negara yang demokratis serta bertanggung jawab. Penerapan sistem pendidikan nasional yang baik dan mencerahkan bagi peserta didik tidak dengan meliberalkan sistem pendidikan, tetapi membangun pemikiran bahwa tidak selalu pemerintah, orang tua dan guru lebih tahu yang terbaik bagi peserta didik. Kementerian Pendidikan dan Kebudayaan perlu melakukan reformasi secara komprehensif terkait dengan pelaksanaan sistem pendidikan nasional dengan cara yang efisien, transparan,dan akuntabel. Pendidikan harus mendapatkan perhatian yang serius bagi setiap bangsa,karena dengan pendidikan akan dapatdilihat maju mundurnya suatu bangsa.Tentu saja bangsa Indonesia tidak ingin hidup terbelakang akibat aspek pendidikan tidak mendapat porsi yang cukup dengan beriringnya berbagai kemajuan di bidanglain. Sehingga penting suatu perekayasaan sistem pendidikan nasional untuk mencerdaskan kehidupan bangsa.

\section{DAFTAR PUSTAKA}

Brooks,J.G \& M.G.Brooks. (1991). The Case For Constractivist Classrooms. ASCD. USA

Escobar, M. (1989). Sekolah Kapitalisme yang Licik. LKIS.Yogyakarta

Tabrani, Z. A. (2017). Sistem Pendidikan di Indonesia Antara Solusi dan Ilusi. https://www.researchgate.net/publication/318587807.

Tilaar, H. A. R. (1990). Pendidikan Dalam Pembangunan Nasional Menyongsong Abad XXI. Jakarta: Balai Pustaka

Tilaar, H. A. R. (2006). Standar Pendidikan Nasional Suatu Tinjauan Kritis. Jakarta: Rineka Cipta

Herwin. (2019). Evaluasi Program Pembelajaran IPS di Sekolah Dasar Negeri 126 Lagoe. Didaktika: Jurnal Pendidikan Sekolah Dasar. Vol. 2, No. 2.

Kemendiknas. (2010). Reformasi Sistem Pendidikan Nasional, Sub: Penguatan Organisasi. Jakarta

Munirah. (2015). Sistem Pendidikan Di Indonesia: Antara Keinginan Dan Realita. Jurnal Auladuna Vol. 2 No. 2.

Nasution, E. (2018). Problematika Pendidikan di Indonesia. Jurnal Mediasi, Vol. 8, No. 1

Purwanti, D. (2018). Efektivitas Kebijakan Penerimaan Peserta Didik Baru Sistem Zonasi Bagi Peserta didik Rawan Melanjutkan Pendidikan. Jurnal Dinamika, Vol 5 No. 4.

Reza, K, E. (2019). Implementasi Kebijakan Sistem Zonasi Terhadap Proses Penerimaan Peserta Didik Baru Kabupaten Lampung Tengah. Skripsi. Fakultas Hukum Universitas Lampung Bandar Lampung

Steinberg,L. (1996). Beyond the Classroom.SimonSchuster. New York. 
Wahyuni, Dinar. (2018). Pro Kontra Sistem Zonasi Penerimaan Peserta Didik Baru Tahun Ajaran 2018/2019. Kajian Singkat Terhadap Isu Aktual dan Strategis Vol. X No.14 Juli 2018: Pusat Penelitian Badan Keahlian DPR RI 